\title{
Effects of ventilation programme and eggshell thickness on hatchability rate and hatching time of broiler eggs
}

\author{
N. Okur" \& S.A. Eratalar \\ Poultry Science Department, Faculty of Agriculture, Bolu Abant Izzet Baysal University, Bolu, Turkey
}

(Submitted 23 August 2019; Accepted 10 October; Published 9 March 2021)

\begin{abstract}
Copyright resides with the authors in terms of the Creative Commons Attribution 4.0 South African License.
See: http://creativecommons.org/licenses/by/4.0/za

Condition of use: The user may copy, distribute, transmit and adapt the work, but must recognize the authors and the South African Journal of Animal Science.
\end{abstract}

\begin{abstract}
The aim of the research was to determine whether enrichment of the atmosphere in an incubator with carbon dioxide $\left(\mathrm{CO}_{2}\right)$ and oxygen $\left(\mathrm{O}_{2}\right)$ and eggshell thickness (EST) affected embryonic death (ED), hatchability of fertile eggs (HFE) and hatching time (HT). A total of 320 Ross 308 eggs were used and the experiment was repeated twice. Eggshell thickness was classified as thin $(<31 \mu \mathrm{m})$, medium $(31-32 \mu \mathrm{m})$ and thick $(>32 \mu \mathrm{m})$. The incubators were operated with their internal atmosphere enriched with $\mathrm{CO}_{2}(1.57 \%$ $\left.\mathrm{CO}_{2} ; 20.23 \% \mathrm{O}_{2}\right)$ or $\mathrm{O}_{2}\left(0.50 \% \mathrm{CO}_{2} ; 22.44 \% \mathrm{O}_{2}\right)$. Embryonic death, HFE and $\mathrm{HT}$ data were monitored at three periods, namely early ( $<486$ hours), middle (486 - 492 hours), and late (492 - 510 hours). Early ED, late ED and hatchability of fertile eggs were not affected by EST or by the incubator's internal atmosphere $(P$ $>0.05)$. Thus, $\mathrm{O}_{2}$ supplementation to the incubator was deemed unnecessary at $822 \mathrm{~m}$ altitude. There was a highly significant interaction between EST and HT. Eggs with shells 31 to $32 \mu \mathrm{m}$ thick hatched at an appreciably greater rate between 486 and 492 hours of incubation $(17 \%)$ than eggs with thicker $(0.6 \%)$ or thinner $(0.4 \%)$ shells in both the $\mathrm{CO}_{2}$ and $\mathrm{O}_{2}$ enriched atmospheres. The hatching rate was significantly higher in the eggs with an intermediate EST than in thick-shelled eggs. A greater proportion of eggs hatched at the late HT as opposed to earlier, regardless of EST.
\end{abstract}

Keywords: broiler, eggshell thickness, hatching time, incubator ventilation programme

"Correspondence: nezihokur@ibu.edu.tr

\section{Introduction}

Successful incubation of broiler eggs depends on management of the incubator (French, 1997; Yildirim \& Yetisir, 2004) and certain characteristics of hatching eggs such as genetics, age, maintenance and feeding conditions of breeders, egg weight (EW), and EST (Kirk et al., 1980; Narushin \& Romanov, 2002; Sarica et al., 2012; Elibol \& Turkoglu, 2014; Hammershoj \& Steenfeldt, 2015; Yamak et al., 2015; Popova et al., 2019). The levels of $\mathrm{CO}_{2}$ and $\mathrm{O}_{2}$ in the incubator reportedly determine the rate of embryonic development and may affect incubation and post-hatching performance (Metcalfe et al., 1981; Lourens, 2007; Molenaar et al., 2010; Tona et al., 2013).

An atmosphere that is low in $\mathrm{O}_{2}$, such as at high altitudes, can affect incubation efficiency and chick quality negatively (Ahmed et al., 2013. The content of $\mathrm{O}_{2}$ in the atmosphere is about $21 \%$ at sea level (Stock \& Metcalfe, 1984). Low $(<17 \%)$ and high $(25 \%) \mathrm{O}_{2}$ levels have both been reported to affect embryonic survival and hatchability negatively (Stock \& Metcalfe, 1984; Lourens et al., 2007; Molenaar et al., 2010). In high altitude (3500 - $4000 \mathrm{~m}$ ) areas, such as India and South America, very low hatchability rates have been reported such as 20\% (Ahmed et al., 2013; Tullet 2013). To compensate for reduced levels of $\mathrm{O}_{2}$, an oxygen concentrator can be used to increase the oxygen level of the atmosphere inside the incubator (Cobb, 2013; Tullet, 2013).

Researchers reported favourable effects from an increase in the level of $\mathrm{CO}_{2}$ in the incubator. A gradual increase of up to $1.5 \%$ in $\mathrm{CO}_{2}$ levels, which should normally be around $1 \%$ in the first 10 days of incubation, improved embryo development, promoted early hatching, and increased overall hatchability (Buys et al., 1998; Onagbesan et al., 2007; Tong et al., 2015).

Eggshell thickness has an important role as an embryonic respiratory component (Hunton, 2005). It can be measured with non-destructive equipment that is produced by a few innovative companies (e.g. Orka Tech Ltd., Israel). Eggshell thickness varies between 33 and $40 \mu \mathrm{m}$ in broiler eggs (Yamak et al., 2015). In 
addition, EST in the range of 35 - $39 \mu \mathrm{m}$ (Huwaida et al., 2015) apparently does not affect embryo mortality or hatchability.

Because of their potential effects on economic criteria, including hatchability of fertile eggs and hatching time, it was hypothesized that differences in the $\mathrm{CO}_{2}$ and $\mathrm{O}_{2}$ levels of the atmosphere inside the incubator and their interrelationship with EST will affect embryonic survival, hatchability of fertile eggs and time of hatching of broiler chicks.

\section{Material and Methods}

The study was conducted in accordance with the Turkish Animal Welfare Act, and all procedures involving handling of eggs and chicks were approved by the Animal Ethics Committee of Bolu Abant Izzet Baysal University (Decision no: 2015/45 dated 30 December 2015). It took place in Bolu Province where more than $30 \%$ of poultry production in Turkey occurs. The average altitude of this province is $822 \mathrm{~m}$.

The entire experiment was done twice under identical conditions. In each experiment, 2880 broiler hatching eggs were obtained from Ross 308 breeder flocks. All eggs were stored for three days before incubation, and the egg storage room was kept at $18{ }^{\circ} \mathrm{C}$ and $75 \%$ relative humidity during this period. Before the incubation period, the eggs were preheated for six hours in incubators set at $24{ }^{\circ} \mathrm{C}$.

The eggs were weighed and classified as heavy $(69.83 \pm 0.25 \mathrm{~g})$, medium $(65.10 \pm 0.10 \mathrm{~g})$, and light $(60.97 \pm 0.21 \mathrm{~g})$, and placed in trays so that there was an equal number of eggs of similar weight in all treatment groups. The incubators (Cimuka 960SH, Cimuka Ltd. Co., Turkey) were located in the incubation laboratory of Bolu Abant Izzet Baysal University Faculty of Agriculture Department of Poultry Science. Each incubator was equipped with six egg trays with a capacity of 80 eggs, and six chick baskets with the same capacity. The six trays were divided into groups of two, according to their location in the incubator. The eggs that were used in this research were positioned in the middle part of each tray. Therefore, 320 hatching eggs were weighed $( \pm 0.1 \mathrm{mg}$ ) individually using an analytical balance (Radwag AS 220.R2, Radwag Balance and Scales, Poland) and numbered. Eggshell thickness was measured with an ultrasonic EST gauge (Orka Tech. Ltd., Israel) with a sensitivity of $\pm 1 \mu \mathrm{m}$ and classified as thin $(<31 \mu \mathrm{m})$, medium (32 - $33 \mu \mathrm{m})$ and thick $(>33 \mu \mathrm{m})$. During the incubation period, both incubators were operated to achieve $37.8^{\circ} \mathrm{C}$ eggshell temperature.

To achieve a $\mathrm{CO}_{2}$-rich atmosphere in one of the incubators, the ventilation flaps were closed during the first 10 days of incubation and $\mathrm{CO}_{2}$ was allowed to increase. After this time, the ventilation flaps were opened and the normal ventilation regime was applied. In the second incubator, an $\mathrm{O}_{2}$-rich atmosphere was achieved with an oxygen concentrator (Hikoneb Oxybreath 10LPM, Kare Medical Ltd. Co., Turkey), which produced $92 \pm 3 \%$ pure $\mathrm{O}_{2}$ and was introduced at approximately $10 \%$ of the total air drawn into the incubator. The $\mathrm{CO}_{2}$ level was measured with Hatch Eco2-01 sensors (Cimuka Ltd., Turkey), and the $\mathrm{O}_{2}$ levels were recorded by PAC 7000 data loggers (Drager Safety AG \& Co., KGaA, Germany). Eggshell temperature values were measured with an infrared ear thermometer (Braun Thermoscan, Braun, Germany). In both incubators relative humidity was maintained at $57.0 \%$ throughout the incubation period. The trays were turned automatically 24 times a day.

On the 18th day of incubation, the eggs were transferred from the trays to the hatching baskets in the same incubators and maintaining their position. The experimental eggs were held in a specially prepared plastic compartment that was covered to maintain the association of eggs and chicks with the treatment to which they had been subjected. Hatching time was categorized as early, middle, and late. To determine HT, the incubators were opened after 486, 492, and 510 hours of incubation. At these times, the eggs were checked, and hatched chicks were counted, recorded, and removed. Hatching rates for each treatment were calculated as:

$$
\text { Hatching rate, } \%=\frac{\text { Number of chicks that hatched in the specified time interval }}{\text { Total number of eggs hatched }} \times 100
$$

Once hatching was finished, EDs were determined as early (0-5 days), middle (6-17 days) and late (18-21 days, and as pipped but unhatched eggs). Percentages of early-, middle-, and late-stage EDs were calculated relative to the total number of eggs set. The percentage hatchability of fertile eggs was expressed relative to the total number of fertile eggs set.

The required number of observations was calculated with PASS 11 (Hintze, 2011) power analysis. The data were analysed using IBM SPSS Statistics 22 (SPSS Inc., 2013). The Shapiro-Wilk test was used to confirm the normal distribution of the data. One-way analysis of variance and post-hoc Tukey test were used to assess the treatment effects. $P$-values lower than 0.05 were considered significant. The results are reported as means \pm standard error. 


\section{Results and Discussion}

The data in Table 1 confirm the categorization of EW as heavy, medium and light and EST as thin, medium and thick. Likewise, they demonstrate the similarity of eggs that were allocated to the treatments $(P$ $>0.05$ ). Overall, the average EW was $65.17 \mathrm{~g}$ with a coefficient of variation (CV) of 6.17 and the average EST was $31.26 \mu \mathrm{m}$ with a CV of 4.34. In the light of these data, the uniformity of the eggs used in the present research was high. These eggs were slightly heavier than those used by Kirk et al. (1980) and had thinner shells compared with other studies (Christensen et al., 1994; Huwaida et al., 2015 and Yamak et al., 2015).

Table 1 Description of experimental materials used to assess effects of the ventilation programme and eggshell thickness on hatchability and hatching time of broiler eggs

\begin{tabular}{lcc}
\hline & Egg weight, $g$ & Eggshell thickness, $\mu \mathrm{m}$ \\
\hline Egg weight & & \\
$\quad$ Heavy & $69.56 \pm 0.24^{\mathrm{a}}$ & $31.38 \pm 0.13$ \\
$\quad$ Medium & $64.98 \pm 0.10^{\mathrm{b}}$ & $31.18 \pm 0.12$ \\
$\quad$ Light & $60.97 \pm 0.20^{\mathrm{c}}$ & $31.20 \pm 0.14$ \\
Incubator atmosphere & & \\
$\quad$ Carbon dioxide rich & $63.77 \pm 0.74$ & $31.33 \pm 0.11$ \\
Oxygen rich & $64.05 \pm 0.71$ & $31.19 \pm 0.11$ \\
Eggshell thickness & & \\
Thin $(<31 \mu \mathrm{m})$ & $64.11 \pm 1.04$ & $29.63 \pm 0.06^{\mathrm{c}}$ \\
$\quad$ Medium $(32$ - 33 $\mu \mathrm{m})$ & $63.69 \pm 0.59$ & $31.49 \pm 0.04^{\mathrm{b}}$ \\
$\quad$ Thick $(>33 \mu \mathrm{m})$ & $66.56 \pm 0.50$ & $33.27 \pm 0.06^{\mathrm{a}}$ \\
Egg position in incubator & & \\
$\quad$ Top & $63.31 \pm 1.31$ & $31.30 \pm 0.13$ \\
Medium & $63.90 \pm 0.87$ & $31.29 \pm 0.13$ \\
Bottom & $64.42 \pm 0.44$ & $30.99 \pm 0.14$ \\
$P$-value & & \\
Egg weight & 0.000 & 0.497 \\
Incubator ventilation programme & 0.878 & 0.344 \\
Eggshell thickness & 0.412 & 0.000 \\
Egg position & 0.679 & 0.162 \\
\hline
\end{tabular}

${ }^{*}$ Carbon dioxide rich $\left(1.57 \% \mathrm{CO}_{2}\right.$ and $\left.20.23 \% \mathrm{O}_{2}\right)$ and oxygen rich $\left(0.50 \% \mathrm{CO}_{2}\right.$ and $\left.22.44 \% \mathrm{O}_{2}\right)$

a,b,c Within a set of observations of a trait, means with common superscripts did not differ with probability $P=0.05$

In the first 10 days of incubation, the atmosphere inside the incubator could be enriched gradually with $\mathrm{CO}_{2}$ by keeping the ventilation flaps closed (Figure 1). Thus, on the tenth day of incubation, eggs in that incubator were exposed to a $\mathrm{CO}_{2}$ level of $1.50 \%$ and an $\mathrm{O}_{2}$ level of $20.25 \%$. In contrast, eggs in the incubator in which the atmosphere was enriched with $\mathrm{O}_{2}$, were exposed to a $\mathrm{CO}_{2}$ level of $0.90 \%$ and an $\mathrm{O}_{2}$ level of $21.50 \%$ at that time. 


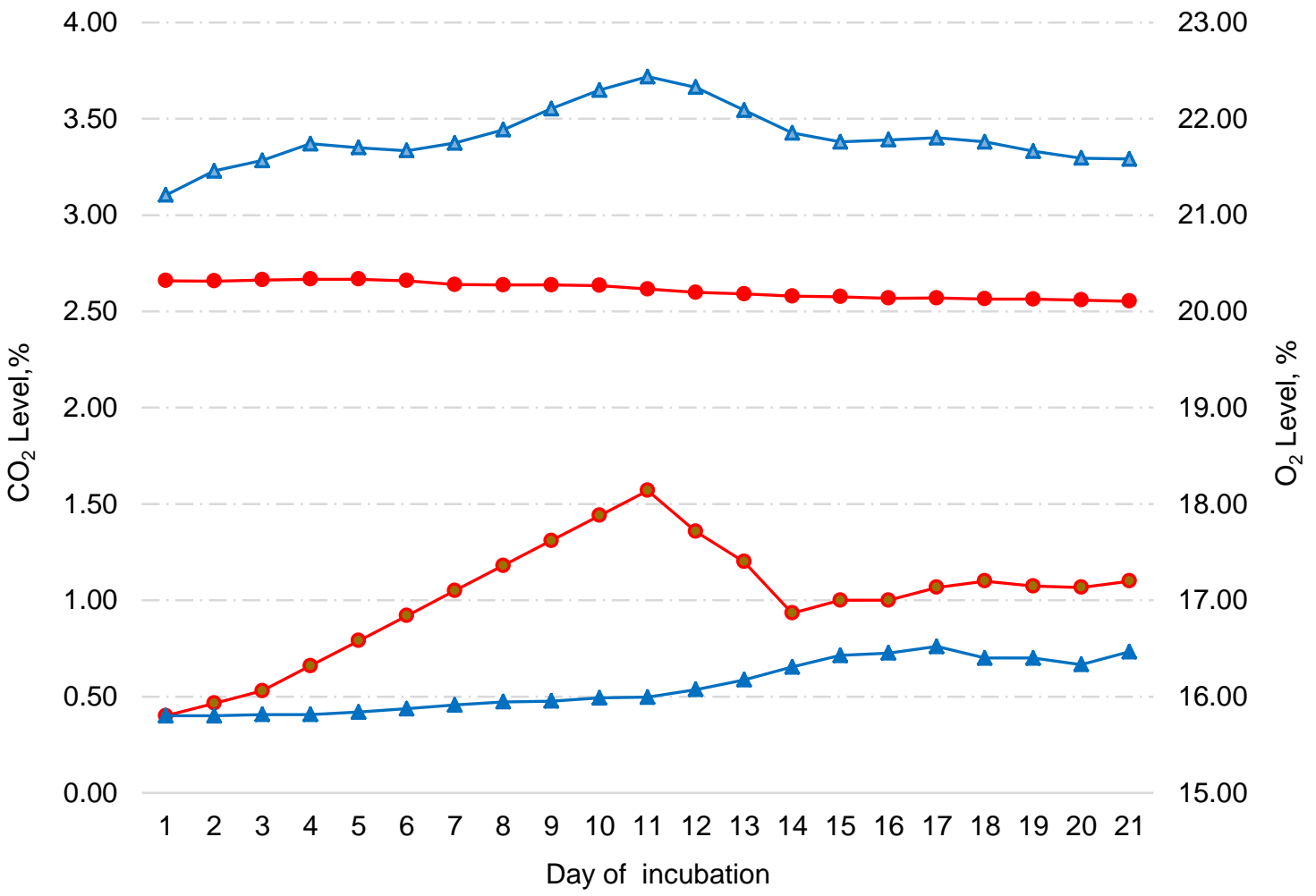

Figure 1 Carbon dioxide and oxygen levels in incubators with enriched atmospheres

Red line: Carbon dioxide $\left(\mathrm{CO}_{2}\right)$ enriched atmosphere; blue line: oxygen $\left(\mathrm{O}_{2}\right)$ enriched atmosphere; top panel and right axis: $\mathrm{O}_{2}$ levels; lower panel and left axis: $\mathrm{CO}_{2}$ levels

Enriching the atmosphere inside the incubator with either $\mathrm{CO}_{2}$ or $\mathrm{O}_{2}$ through day 10 of incubation did not affect $(P>0.05)$ the levels or timing of ED or HFE (Table 2). These results differ from the observations of Tona et al. (2013), in which a gradual increase in level of $\mathrm{CO}_{2}$ up to $1.50 \%$ improved embryo development, promoted early hatching, and increased the hatchability of chicken eggs. However, the broiler breeding companies indicated that $\mathrm{O}_{2}$ enrichment of the atmosphere inside an incubator should not be expected to alter embryo development or hatchability in places with an altitude less than $1000 \mathrm{~m}$ above sea level. The location in which the current study was conducted is $822 \mathrm{~m}$ above sea level (Cobb, 2013; Tullet, 2013). Accordingly, it can be concluded that in areas with similar altitude, the use of an oxygen concentrator to maintain the $\mathrm{O}_{2}$ level in the incubator is not necessary. Eggshell thickness did not affect the timing and level of ED or HFE $(P<0.05)$. This result was consistent with the findings of Huwaida et al. (2015), who reported that EST did not affect ED and hatchability. The interaction of EST and atmospheric conditions in the incubator did not affect these traits $(P>0.05)$, either. 
Table 2 Embryonic death and hatchability of fertile eggs as related to differences in eggshell thickness and atmospheric conditions inside the incubator

\begin{tabular}{|c|c|c|c|c|}
\hline Shell thickness & Atmosphere & Early embryonic death & Later embryonic deaths & $\begin{array}{c}\text { Hatchability of fertile } \\
\text { eggs }\end{array}$ \\
\hline$<31 \mu \mathrm{m}$ & $\mathrm{CO}_{2}$ enriched & $1.39 \pm 1.39$ & $5.28 \pm 3.11$ & $93.33 \pm 3.20$ \\
\hline $31-32 \mu \mathrm{m}$ & $\mathrm{CO}_{2}$ enriched & $2.70 \pm 1.55$ & $6.25 \pm 4.49$ & $91.05 \pm 4.41$ \\
\hline$>32 \mu \mathrm{m}$ & $\mathrm{CO}_{2}$ enriched & $3.79 \pm 2.60$ & $14.70 \pm 9.01$ & $81.52 \pm 9.39$ \\
\hline$<31 \mu \mathrm{m}$ & $\mathrm{O}_{2}$ enriched & $6.13 \pm 4.20$ & $7.87 \pm 4.76$ & $86.00 \pm 5.78$ \\
\hline $31-32 \mu \mathrm{m}$ & $\mathrm{O}_{2}$ enriched & $2.96 \pm 1.77$ & $1.29 \pm 0.87$ & $95.75 \pm 2.00$ \\
\hline$>32 \mu \mathrm{m}$ & $\mathrm{O}_{2}$ enriched & $5.00 \pm 3.56$ & $4.17 \pm 2.85$ & $90.83 \pm 4.72$ \\
\hline \multicolumn{5}{|l|}{$P$-values } \\
\hline \multicolumn{2}{|c|}{ Incubator atmosphere } & 0.333 & 0.295 & 0.644 \\
\hline \multicolumn{2}{|c|}{ Eggshell thickness } & 0.846 & 0.481 & 0.389 \\
\hline \multicolumn{2}{|l|}{ Interaction } & 0.838 & 0.502 & 0.462 \\
\hline
\end{tabular}

The highly significant interaction effect resulted primarily from eggs with shells 31 to $32 \mu \mathrm{m}$ thick, which had an appreciably greater rate of hatching between 486 and 492 hours of incubation than eggs with thicker or thinner shells in the $\mathrm{CO}_{2}$ - and $\mathrm{O}_{2}$-enriched atmospheres (Table 3). In addition, eggs with this intermediate shell thickness hatched at appreciably higher rates than thin- or thick-shelled eggs. A greater proportion of eggs hatched at the late HT than at the earlier time, regardless of EST. For the late hatching, the hatching rate was significantly higher in eggs with an intermediate EST than in thick-shelled eggs.

Table 3 Mean hatching rates (\%) for the highly significant interaction of eggshell thickness and hatching time in incubators with carbon dioxide- and oxygen-enriched atmospheres

\begin{tabular}{lcccc}
\hline Eggshell thickness & Hatching time & Carbon dioxide & Oxygen & Average \\
\hline$<31 \mu \mathrm{m}$ & $<486 \mathrm{~h}$ & $1.52 \pm 0.85^{\mathrm{c}}$ & $4.17 \pm 4.17^{\mathrm{b}}$ & $2.90 \pm 2.18^{\mathrm{cd}}$ \\
$<31 \mu \mathrm{m}$ & $486-492 \mathrm{~h}$ & $0.38 \pm 0.38^{\mathrm{c}}$ & $0.35 \pm 0.35^{\mathrm{b}}$ & $0.36 \pm 0.25^{\mathrm{d}}$ \\
$<31 \mu \mathrm{m}$ & $492-510 \mathrm{~h}$ & $14.39 \pm 4.40^{\mathrm{bc}}$ & $16.67 \pm 4.62^{\mathrm{bc}}$ & $15.58 \pm 3.13^{\mathrm{bc}}$ \\
$31-32 \mu \mathrm{m}$ & $<486 \mathrm{~h}$ & $0.38 \pm 0.38^{\mathrm{c}}$ & $13.89 \pm 8.84^{\mathrm{bc}}$ & $7.43 \pm 4.74^{\mathrm{bcd}}$ \\
$31-32 \mu \mathrm{m}$ & $486-492 \mathrm{~h}$ & $17.42 \pm 9.68^{\mathrm{bc}}$ & $16.67 \pm 6.71^{\mathrm{bc}}$ & $17.03 \pm 5.67^{\mathrm{bc}}$ \\
$31-32 \mu \mathrm{m}$ & $492-510 \mathrm{~h}$ & $43.94 \pm 5.28^{\mathrm{a}}$ & $29.51 \pm 5.72^{\mathrm{a}}$ & $36.41 \pm 4.12^{\mathrm{a}}$ \\
$>32 \mu \mathrm{m}$ & $<486 \mathrm{~h}$ & $0.38 \pm 0.38^{\mathrm{c}}$ & $0.35 \pm 0.35^{\mathrm{b}}$ & $0.36 \pm 0.25^{\mathrm{d}}$ \\
$>32 \mu \mathrm{m}$ & $486-492 \mathrm{~h}$ & $0.76 \pm 0.51^{\mathrm{C}}$ & $0.35 \pm 0.35^{\mathrm{b}}$ & $0.54 \pm 0.30^{\mathrm{d}}$ \\
$>32 \mu \mathrm{m}$ & $492-510 \mathrm{~h}$ & $20.83 \pm 4.67^{\mathrm{b}}$ & $18.06 \pm 3.71^{\mathrm{b}}$ & $19.38 \pm 2.90^{\mathrm{b}}$
\end{tabular}

Carbon dioxide $\left(1.57 \% \mathrm{CO}_{2}\right.$ and $\left.20.23 \% \mathrm{O}_{2}\right)$ and oxygen $\left(0.50 \% \mathrm{CO}_{2}\right.$ and $\left.22.44 \% \mathrm{O}_{2}\right)$ enriched atmospheres during the first 10 days of incubation

a,b,c,d Means with a common superscript were not different with probability $P=0.05$

Prolonged holding of chicks without food and water in an incubator can lead to their becoming dehydrated and losing weight. The results for the effect of EST show that it is an important parameter of egg quality (Ketta \& Tumova, 2016; Dahloum et al., 2018; Ketta \& Tumova, 2018) and of HT. It is known that EST decreases as the egg yield increases (Christensen et al., 1994; Yamak et al., 2015). Modern technology allows non-destructive measurement of EST (Khaliduzzaman et al., 2020; Kibala et al., 2015) and could be used in managing the incubation process. An alternative way of reducing holding time would be to empty the incubators twice instead of once. 


\section{Conclusion}

Although they are beneficial at higher altitudes, changes in the internal atmosphere of the incubators were deemed unnecessary at $822 \mathrm{~m}$ altitude. However, HT was affected by EST, and the incubation process might be made more efficient and the welfare of hatched chicks could be improved by sorting the eggs according to EST when placing them in an incubator.

\section{Acknowledgements}

This research was supported by BAP Project No. 2016.10.03.990 awarded to Bolu Abant İzzet Baysal University (BAIBU) and the equipment was provided by this project and additional funding (BAP project numbers 2015.10.03.881, 2015.103.88 and 2016.10.03.1029). The BAIBU and Beypi Inc. (beypiliç®) for their support which allowed the first author to realize the research.

\section{Authors' Contributions}

NO designed the study and analysed data. NO and SAE collected data and prepared the manuscript.

\section{Conflict of Interest Declaration}

The authors declare that they have no affiliations with any organization or entity with any financial or non-financial interest that could bias the subject matter and outcomes discussed in this manuscript.

\section{References}

Ahmed, M., Biswas, A., Roy, B.G. \& Srivastava R.B., 2013. Frequently encountered problems during hatching in cold arid high altitude regions such as Ladakh in India: Causes and remedies. World's Poult. Sci. J. 69, 897-901. DOI: $10.1017 /$ S0043933913000895

Buys, N.E., Dewil, E., Gonzalez, E. \& Decuypere, E., 1998. Different $\mathrm{CO}_{2}$ levels during incubation interact with hatching time and ascites susceptibility in two broiler lines selected for different growth rate. Avian Pathol. 27, 605-612. DOI: 10.1080/03079459808419391

Christensen, V.L. \& Nestor, K.E., 1994. Changes in functional qualities of turkey eggshells in strains selected for Increased egg production or growth. Poult. Sci. 73, 1458-1464. DOI: 10.3382/ps.0731458

Cobb, 2013. Cobb hatchery management guide. Publication No L-1030-03. Cobb-Vantress Inc., Siloam Springs, Arkansas, USA.

Dahloum, L., Yakubu, A. \& Halbouche M., 2018. Effects of housing system and plumage colour on egg quality characteristics of indigenous Naked-Neck chickens. Livest. Res. Rural 30, 206. (ISSN: 01212-3784

Elibol, O. \& Turkoglu, M., 2014. Embryo development and hatchery. In: M. Turkoglu \& M. Sarica (eds.), 2014. Poultry science. 4th edition. Bey Ofset, Ankara, Turkey.

French, N.A., 1997. Modeling incubation temperature: The effects of incubator design, embryonic development, and egg size. Poult. Sci. 76, 124-133. DOI: 10.1093/ps/76.1.124

Hammershøj, M. \& Steenfeldt, S., 2015. Organic egg production II: The quality of organic eggs is influenced by hen genotype, diet and forage material analyzed by physical parameters, functional properties and sensory evaluation. Anim. Feed Sci. Tech. 208, 182-197. DOI: 10.1016/j.anifeedsci.2015.07.012

Hintze, J.L., 2011. PASS 11. NCSS, LLC. Kaysville, UT, USA.

Hunton, P., 2005. Research on eggshell structure and quality: An historical overview. Braz. J. Poult. Sci. 7,67-71.

Huwaida, E.E., Sakin, M.A.I.Y., Elagib, H.A.A., Bakhiet, E., Dousa, B.M. \& Elamin, K.M., 2015. Effect of egg weight and egg shell thickness on hatchability and embryonic mortality of Cobb broiler breeder eggs. Global J. of Anim. Sci. Res. 3, 186-190.

Ketta, M. \& Tumova, E., 2016. Eggshell structure, measurements, and quality-affecting factors in laying hens. Czech J. Anim. Sci. 61: 299-309. DOI: 10.17221/46/2015-CJAS

Ketta, M. \& Tumova, L., 2018. Relationship between eggshell thickness and other eggshell measurements in eggs from litter and cages. Ital. J. Anim. Sci. 17, 234-239. DOI: 10.1080/1828051X.2017.1344935

Khaliduzzaman, A., Konagaya, K., Suzuki, T., Kashimori, A., Kondo, N. \& Ogawa, Y., 2020. A nondestructive eggshell thickness measurement technique using Terahertz waves. Sci. Rep. 10, 1052. https://doi.org/10.1038/s41598020-57774-5

Kibala, L., Rozempolska-Rucinska, I., Kasperek, K., Zieba, G. \& Lukaszewicz, M., 2015. Ultrasonic eggshell thickness measurement for selection of layers. Poult. Sci. 94, 2360-2363. DOI: 10.3382/ps/pev254

Kirk, S., Emmans, G.C., Donald, R.M. \& Arnot, D., 1980. Factors affecting the hatchability of eggs from broiler breeders. Brit. Poult. Sci. 21, 37-53. DOI: 10.1080/00071668008416633

Lohmann, 2018. Hatchery management guide. Publication 09/18. Lohmann Tierzucht GmbH. Am Seedich 9-11, Cuxhaven, Germany.

Lourens, A., Van Den Brand, H., Heetkamp, M.J.W. Meijerhof, R. \& Kemp, B., 2007. Effects of egg shell temperature and oxygen concentration on embryo growth and metabolism during incubation. Poult. Sci. 86, 2194-2199. DOI: 10.1093/ps/86.10.2194

Metcalfe, J., McCutcheon, I.E., Francisco, D.I., Metzenberg, A.B. \& Welch, J.E., 1981. Oxygen availability and growth of the chick embryo. Resp. Physiol. 46, 81-88. DOI: 10.1016/0034-5687(81)90091-8

Molenaar, R., Meijerhof, R., Van den Anker, I., Heetkamp, M.J.W., Van den Borne, J.J.G.C., Kemp, B. \& Van den Brand, $\mathrm{H}$., 2010. Effect of eggshell temperature and oxygen concentration on survival rate and nutrient utilization in chicken embryos. Poult. Sci. 89, 2010-2021. DOI: 10.3382/ps.2010-00787 
Narushin, V.G. \& Romanov, M.N., 2002. Egg physical characteristics and hatchability. World's Poult. Sci. 58, $297-303$. DOI: 10.1079/WPS20020023

Onagbesan, O., Bruggeman, V., De Smit, L., Debonne, M., Witters, A., Tona, K. \& Everaert, N., 2007. Gas exchange during storage and incubation of Avian eggs: Effects on embryogenesis, hatchability, chick quality and post-hatch growth. World's Poult. Sci. 63, 557-573 DOI: 10.1017/S0043933907001614

Popova, T., Petkov, E., Ayasan, T. \& Ignatova, M., 2020. Quality of eggs from layers reared under alternative and conventional system. Braz. Poult. Sci. 22, 1-8. DOI: 10.1590/1806-9061-2019-1172

Sarica, M., Onder, H. \& Yamak, U.S., 2012: Determining the most effective variables for egg quality traits of five hen genotypes. Int. J. Agric. Biol. 14, 235-240. ISSN:1814-9596 11-556/DNT/2012/14-2-235-240

Stock, M.K., \& Metcalfe, J., 1984. Stimulation of growth of the chick embryo by acute hyperoxia. Resp. Physiol. 58, 351358. 358 DOI: 10.1016/0034-5687(84)90011-2

Tona, K., Everaert, N., Willemsen, H., Gbeassor, M., Decuypere, E. \& Buyse, J., 2013. Effects of interaction of incubator $\mathrm{CO}_{2}$ levels and mixing hatching eggs of different embryo growth trajectory on embryo physiological and hatching parameters. Brit. Poult. Sci. 54, 545-551. DOI: 10.1080/00071668.2013.807907

Tong, Q., McGonnell, I., Roulston, N., Bergoug, H., Romanini, C., Garain, P., Eterradossi, N., Exadaktylos, V., Bahr, C. \& Berckmans, D., 2015. Higher levels of $\mathrm{CO}_{2}$ during late incubation alter the hatch time of chicken embryos. British Poult. Sci. 56, 503-509. DOI: 10.1080/00071668.2015.1041097

Tullet, S., 2013. Incubating eggs at high altitude. Ross Technote: 0713-AVNR-027. Aviagen Inc., Newbridge, Midlothian, Scotland, UK.

Yamak, U.S., Sarica, M., Boz, M.A. \& Onder, H., 2015. The effect of eggshell thickness on some hatching traits of partridges. J. Fac. Vet. Med. Kafkas Uni. 21, 421-424. DOI: 10.1590/1806-9061-2015-0039

Yildirim, I. \& Yetisir, R., 2004. Effects of different hatcher temperatures on hatching traits of broiler embryos during the last five days of incubation. S. Afr. J. Anim. Sci. 34, 211-216. 